\title{
EXPRESSION OF P21 IS DEPENDENT ON OR INDEPENDENT OF P53 IN CARCINOMA EX PLEOMORPHIC ADENOMA (UNDIFFERENTIATED AND ADENOCARCINOMA TYPES)
}

\author{
Bassel Tarakji, Kusai Baroudi, Salah Hanouneh, Mohammad Z. Nassani, \\ Abdullah M. Alotaibi, M. Yaser Kharma, Saleh N. Azzeghaiby
}

Alfarabi Dental School, Kingdom of Saudi Arabia

\begin{abstract}
Our study is aimed to characterize alteration in the immunohistochemical expression of p21 and p53 in normal tissue of the salivary gland surrounding carcinoma arising in pleomorphic adenoma, and the tumor cells of carcinoma arising in pleomorphic adenoma as well as to identify whether the induction of expression p 21 is dependent on or independent of $\mathrm{p} 53$ in carcinoma arising in pleomorphic adenoma. A selected series of 27 cases of carcinoma ex pleomorphic adenoma (undifferentiated and adenocarcinoma types) was examined.

The results showed that p21 and p53 expression was negative in the most components of normal tissue of the salivary gland surrounding carcinoma arising in pleomorphic adenoma. p21 was strongly expressed in carcinoma cells in 9 $33.3 \%$ ) cases out of 27. p53 was strongly expressed in carcinoma cells in $10(37 \%)$ cases out of 27. Also a co-expression of p21 and p53 showed negative nuclear staining in 9 cases, while 8 cases expressed positive staining. p21 expressed negative nuclear staining in 4 cases but p53 expressed positive staining in the same cases. p21 expressed positive nuclear staining in 6 cases but p53 expressed negative nuclear staining in the same cases.

Our data suggest that inactivation of p53 and p21 may play an important role in the evolution of carcinoma ex pleomorphic adenoma. Also p21 behaves as dependent on or independent of $\mathrm{p} 53$ in carcinoma arising in pleomorphic adenoma.
\end{abstract}

Key words: p21 expression, p53 expression, pleomorphic salivary adenoma, carcinoma ex pleomorphic adenoma.

\section{Introduction}

Carcinoma ex pleomorphic adenoma (CPA) is considered to be a malignant transformation product of preexisting pleomorphic adenoma [1]. Carcinoma ex pleomorphic adenoma is the most common malignant mixed tumor and has been estimated to account for $10 \%$ of all salivary gland malignancies [2]. The current studies of the molecular biology of cancers have demonstrated that the loss of function of the tumor suppressor gene such as p53 and p21 may lead to the development of many different cancer types [3-6]. Mutation of the p53 tumor suppressor gene, located on the short arm of chromosome 17 , is among the most commonly detected genetic abnormalities in human neoplasia. p21 is a cell cycle regulatory protein encoded by the p21 WAF 1 gene which is located on chromosome 6p21.2 $[7,8]$. It is believed that the inhibitory effects on cell division by p21 are related to cancerous change of normal cells, regulation, cell differentiation and induction of apoptosis involving p53 and $\mathrm{Rb}$ [9]. The aim of this study was to characterize the alterations and aberrations 
in the expression of p21 and p53 in carcinoma ex pleomorphic adenoma and also to evaluate whether p21 expression in carcinoma ex pleomorphic adenoma was functionally related or unrelated to p53 expression.

\section{Materials and methods}

\section{Case selection}

A selected series of 27 cases of carcinoma ex pleomorphic adenoma was retrieved from the files of the Oral Pathology Department in Alfarabi Dental School (Table I). Normal tissue of the salivary gland surrounding the tumour was used as a control in 27 cases of carcinoma arising in pleomorphic adenoma. The immunohistochemical expressions of antibodies against p21 and p53 were examined in the selected cases. The criteria for defining carcinoma ex pleomorphic adenoma proposed by Nagao et al. [10] were used to select and reclassify our cases of carcinoma ex pleo- morphic adenoma. According to the World Health Organization histological classification published in 2005, malignant changes in the pleomorphic adenoma include three different types: CPA, carcinosarco$\mathrm{ma}$, and metastasizing pleomorphic adenoma. The inclusion criteria for carcinoma ex pleomorphic adenoma comprised major gland primary lesions (parotid or submandibular) and the macroscopic features that suggest malignant transformation in pleomorphic adenoma including poorly defined and/or infiltrative tumor margins, the presence of foci of hemorrhage, and necrosis. Also the co-existent benign and malignant elements are considered as well. Benign elements can be pleomorphic adenoma within the tumor mass, biopsy proven history of previous pleomorphic adenoma indicating that it was in the same location as the subsequent carcinoma. Malignant elements can be undifferentiated carcinoma, adenocarcinoma, and multiple patterns of differentiation including undifferentiated or adenocarcino-

Table I. Clinical data of 27 carcinoma ex pleomorphic adenomas cases (CPA)

\begin{tabular}{|c|c|c|c|c|c|}
\hline CPA CASES & AGE (YEARS) & GENDER & GLAND & HISTOLOGICAL SUBTYPE & METASTASIS TO LYMPH NODES* \\
\hline 1 & 77 & $\mathrm{~F}$ & parotid & adenocarcinoma & yes \\
\hline 2 & 28 & $\mathrm{M}$ & parotid & adenocarcinoma & no \\
\hline 3 & 78 & M & submandibular & undifferentiated & yes \\
\hline 4 & 45 & $\mathrm{M}$ & parotid & undifferentiated & yes \\
\hline 5 & 76 & $\mathrm{~F}$ & parotid & undifferentiated & no \\
\hline 6 & 82 & $\mathrm{~F}$ & parotid & undifferentiated & no \\
\hline 7 & 71 & M & parotid & adenocarcinoma & no \\
\hline 8 & 67 & $\mathrm{M}$ & submandibular & undifferentiated & yes \\
\hline 9 & 63 & $\mathrm{M}$ & submandibular & undifferentiated & yes \\
\hline 10 & 55 & $\mathrm{M}$ & submandibular & undifferentiated & yes \\
\hline 11 & 73 & $\mathrm{M}$ & parotid & undifferentiated & yes \\
\hline 12 & 71 & $\mathrm{M}$ & parotid & undifferentiated & no \\
\hline 13 & 64 & $\mathrm{M}$ & parotid & undifferentiated & yes \\
\hline 14 & 60 & $\mathrm{~F}$ & parotid & undifferentiated & yes \\
\hline 15 & 49 & $\mathrm{~F}$ & submandibular & undifferentiated & no \\
\hline 16 & 39 & $\mathrm{~F}$ & parotid & undifferentiated & yes \\
\hline 17 & 56 & $\mathrm{M}$ & parotid & undifferentiated & no \\
\hline 18 & 45 & $\mathrm{~F}$ & parotid & undifferentiated & yes \\
\hline 19 & 57 & $\mathrm{M}$ & parotid & undifferentiated & yes \\
\hline 20 & 66 & $\mathrm{~F}$ & parotid & undifferentiated & no \\
\hline 21 & 86 & $\mathrm{~F}$ & submandibular & undifferentiated & yes \\
\hline 22 & 17 & $\mathrm{~F}$ & parotid & undifferentiated & no \\
\hline 23 & 78 & $\mathrm{M}$ & submandibular & undifferentiated & yes \\
\hline 24 & 26 & $\mathrm{M}$ & parotid & undifferentiated & no \\
\hline 25 & 31 & $\mathrm{~F}$ & parotid & undifferentiated & no \\
\hline 26 & 71 & $\mathrm{M}$ & parotid & undifferentiated & no \\
\hline 27 & 71 & $\mathrm{M}$ & parotid & undifferentiated & no \\
\hline
\end{tabular}


ma patterns. Exclusion criteria for carcinoma ex pleomorphic adenoma include other well-recognized salivary carcinomas and those of uncertain type included in the current WHO histological classification of tumors [11]. Microscopic slides stained with hematoxylin and eosin were reviewed by two pathologists to confirm the histopathological diagnosis and to reclassify the studied cases. The carcinoma cases were classified according to the above-mentioned criteria as undifferentiated carcinoma or adenocarcinoma. The ethical approval was provided by the research ethics committee (Ref. 05/109).

\section{Immunohistochemistry}

Paraffin-embedded tumor samples stored in pathology laboratory files were used in this study. A series of 4$\mu \mathrm{m}$-sections was consecutively cut from all 27 specimens. The sections were deparaffinized in xylene and rehydrated through graded alcohols. Sections were processed using the streptavidin-biotin-peroxidase method. Briefly, the endogenous peroxidase was blocked by $3 \%$ hydrogen peroxidase for $5 \mathrm{~min}$ followed by TBS (trisbuffered saline) wash. Nonspecific immunoreactivity was blocked by incubation with normal goat serum for 20 minutes. A purified mouse anti-human monoclonal antibody p21 (Pharmingen, San Diego) was diluted to $10 \mu \mathrm{l} / \mathrm{ml}$ in $20 \mu \mathrm{l} / \mathrm{ml}$ tris-buffered saline containing
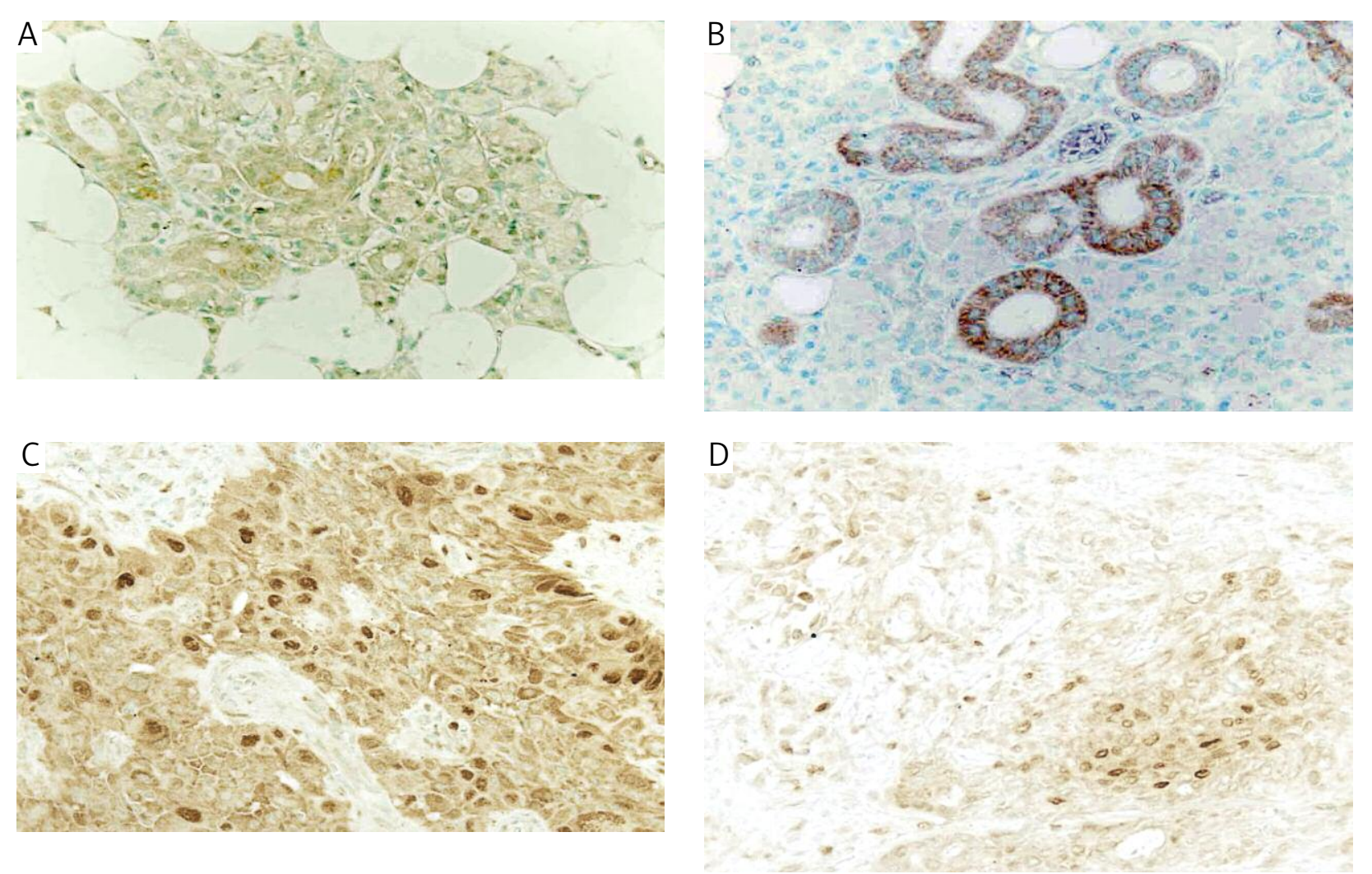

Fig. 1. Nuclear staining of p21 in normal tissue surrounding carcinoma arising in pleomorphic adenoma (original magnification $40 \times)$. A - p21 negative control; B - negative nuclear staining of p21 in ductal and acinar cells in parotid gland; $\mathrm{C}$ - strong nuclear staining of p21 in CPA; D - moderate nuclear staining of p21 in CPA
$0.1 \%$ bovine serum albumin for one hour and fifteen minutes at room temperature. A primary antibody P53 monoclonal mouse antihuman (clone, D-O7: Dako) was diluted to $1: 25(40 \mu \mathrm{l} / \mathrm{ml})$ in tris-buffered saline (TBS) containing $0.1 \%$ bovine serum albumin for 2 hours at room temperature. All sections were washed by TBS for 5 minutes. Sections were incubated with the biotinylated secondary antibody reagent for 30 minutes followed by TBS wash for 5 minutes. Slides were incubated with streptavidin and horseradish peroxidase for $30 \mathrm{~min}$ utes followed by TBS (tris-buffered saline) wash for 5 minutes and incubated with a prepared chromogenic substrate solution (Diaminobenzidine) for 15 minutes. Sections were counterstained with $0.25 \%$ methyl green in distilled water for 5 minutes. Sections were dehydrated and mounted in Depax. Squamous cell carcinoma was used as a positive control. A negative control was used only with substitution of the primary antibody with TBS (Figs. 1A, 2A). The percentage of p35 and p21 positive nuclei was semi-quantitatively assessed by two independent observers and scored as negative (0) no expression of nuclear protein, (1) weak staining: $0-25 \%$ of the total cells show positive staining in the nucleus, (2) moderate staining: $>25-75 \%$ of the total cells in the test area show positive nuclear staining, and (3) strong staining: $>75-100 \%$ of cells show positive nuclear staining. 


\section{Statistical analysis}

Cells of carcinomatous component of the CPA were always scored. The statistical analysis included the use of descriptive statistics; frequencies proportion. Also, statistical analyses, including Mann-Whitney and Wilcoxon's nonparametric tests (ordinal data), were performed on the data. All statistical tests were two-sided and $\mathrm{p}$-values less than 0.05 were considered to be statistically significant.

\section{Results}

p21 expression in the control group (normal tissue) surrounding carcinoma arising in pleomorphic adenoma

Of the 27 cases, p21 expression of the non-tumor duct cells was negative in $25(92.59 \%)$ and weak in 2 cases $(7.40 \%)$ cases with weak staining. p21 (nuclear staining of the acinar cells) showed negative staining in $27(100 \%)$ cases out of 27 (Fig. 1B). p21 (nuclear staining in stroma) was negative in $27(100 \%)$ cases out of 27 .
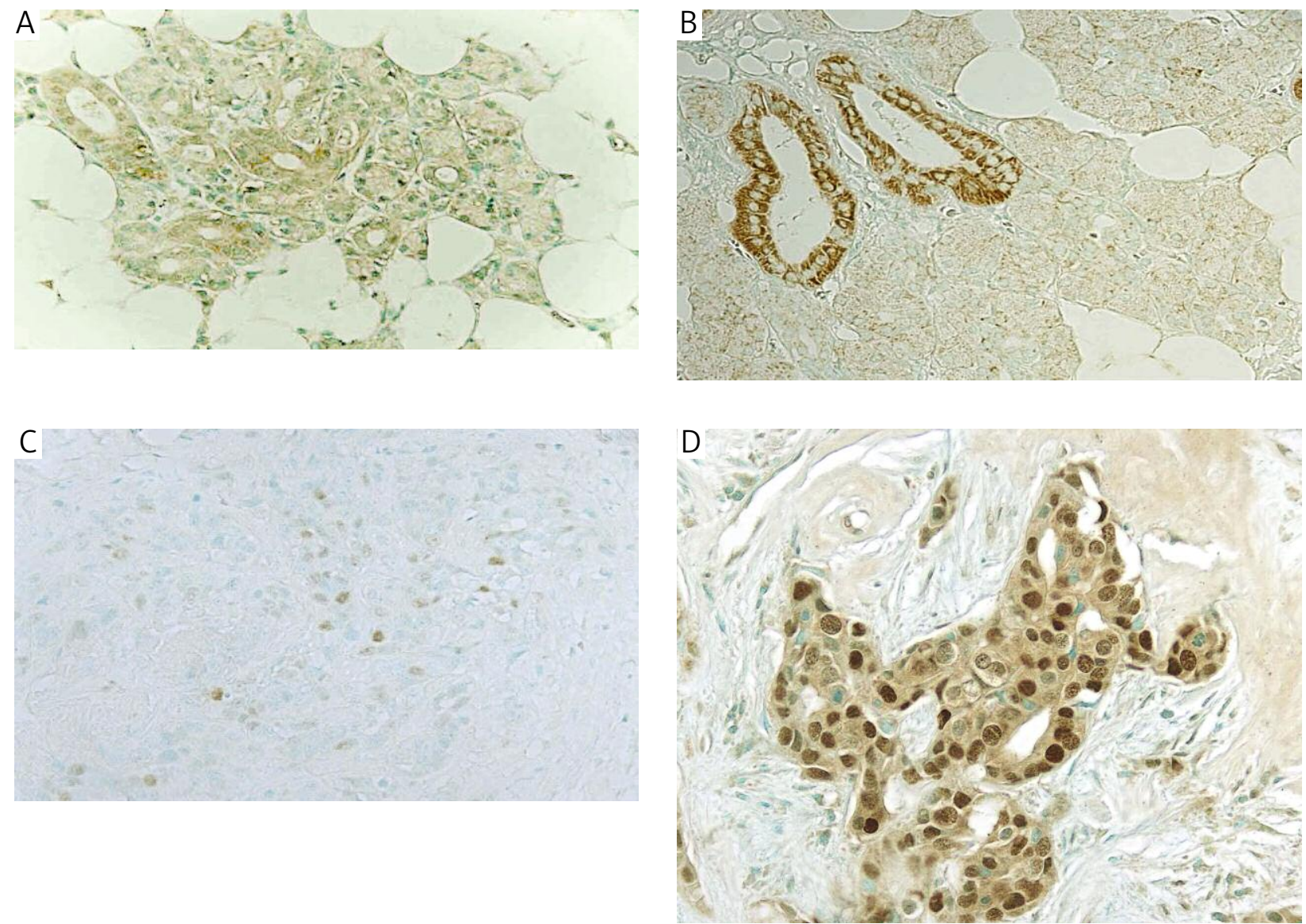

Fig. 2. Nuclear staining of $\mathrm{p} 53$ in normal tissue surrounding carcinoma arising in pleomorphic adenoma (original magnification $40 \times$ ). A - p53 negative control; B - negative nuclear staining of p53 in ductal and acinar cells in parotid gland; $\mathrm{C}-$ moderate nuclear staining of $\mathrm{p} 53$ in carcinoma arising in pleomorphic adenoma; D - strong staining of $\mathrm{p} 53$ in carcinoma arising in pleomorphic adenoma 
Table II. p21 and p53 co-expression of the nuclear staining in carcinoma cases

\begin{tabular}{|c|c|c|}
\hline CPA CASES & P53 & $\mathrm{P} 21$ \\
\hline 1 & negative & negative \\
\hline 2 & negative & positive \\
\hline 3 & positive & positive \\
\hline 4 & negative & negative \\
\hline 5 & negative & positive \\
\hline 6 & positive & positive \\
\hline 7 & negative & positive \\
\hline 8 & positive & negative \\
\hline 9 & negative & positive \\
\hline 10 & positive & positive \\
\hline 11 & negative & negative \\
\hline 12 & negative & negative \\
\hline 13 & positive & positive \\
\hline 14 & negative & negative \\
\hline 15 & negative & positive \\
\hline 16 & negative & positive \\
\hline 17 & positive & negative \\
\hline 18 & negative & negative \\
\hline 19 & negative & negative \\
\hline 20 & negative & negative \\
\hline 21 & negative & negative \\
\hline 22 & positive & positive \\
\hline 23 & positive & positive \\
\hline 24 & positive & negative \\
\hline 25 & positive & negative \\
\hline 26 & positive & positive \\
\hline 27 & positive & positive \\
\hline
\end{tabular}

nificant difference ( $\mathrm{p}$ value $<0.001$ ) between $\mathrm{p} 53$ expression in the nuclei of duct cells in normal tissue surrounding carcinoma arising in pleomorphic adenoma (control group) and the tumor area.

\section{p21 expression in carcinoma arising in pleomorphic adenoma}

p21 was strongly expressed in carcinoma cells in 9 (33.3\%) cases out of 27 (Fig. 1C). 5 (18.5\%) cases showed moderate staining (Fig. 1D), 5 (18.5\%) cases expressed low staining, and 8 cases $(29.6 \%)$ - negative staining. Wilcoxon test showed a significant difference ( $\mathrm{p}$ value $<0.001$ ) between $\mathrm{p} 21$ expression in the nuclei of duct cells in normal tissue surrounding carcinoma arising in pleomorphic adenoma (control group) and the tumor area.

\section{Comparison of $\mathrm{p} 21$ and $\mathrm{p} 53$ in carcinoma arising in pleomorphic adenoma}

It was considered that p21 and p53 strong and moderate nuclear staining was classified as positive, and an indicator for altered $\mathrm{p} 21$ and $\mathrm{p} 53$ carcinoma arising in PSA. Low and negative nuclear staining was classified as negative and indicated the wild type (non altered $\mathrm{p} 21$, and non altered p53). In carcinoma arising in pleomorphic adenoma, p21 staining was positive in 14 $(51.8 \%)$ cases out of 27 , and $\mathrm{p} 53$ staining was positive in $12(44.4 \%)$ cases out of 27. Mann-Whitney test showed no significant difference ( $\mathrm{p}$ value $>0.001$ ) between expression of $\mathrm{p} 53$ and $\mathrm{p} 21$ of the nuclear positive staining in 27 cases of carcinoma arising in pleomorphic adenoma.

\section{Co-expression of $\mathrm{p} 21$ and $\mathrm{p} 53$ in carcinoma arising in pleomorphic adenoma}

The nuclear staining in the carcinoma cases was reclassified to study the relation between p21 and p53. Low and negative staining was considered negative and moderate, while strong nuclear staining was considered positive.

p21 and p 53 showed negative nuclear staining in 9 cases, while 8 cases expressed positive staining. p21 expressed negative nuclear staining in 4 cases but p53 expressed positive staining in the same cases. p21 expressed positive nuclear staining in 6 cases but p53 expressed negative nuclear staining in the same cases (Table II). This means p21 behaves as dependent on or independent of p53. p21 expression in carcinoma arising in pleomorphic adenoma is shown in Fig. 7.

\section{Discussion}

No study has been published regarding p21 expression dependent on or independent of $\mathrm{p} 53$ in salivary glands and particularly in carcinoma arising in pleomorphic adenoma.

p21 WAF 1 is synthesized in order to arrest the cell cycle (G1 or S) through both dependent and independent $\mathrm{p} 53$ pathways [9]. It has been reported that $\mathrm{p} 21 \mathrm{ex}-$ pression in oral cancer was functionally unrelated to $\mathrm{p} 53$ expression (Yook and Kim [12]). El Deiry et al. [7] found that p21 was induced in p53 mediated G1 arrest and apoptosis. Michalides et al. [5] demonstrated a pathway for $\mathrm{p} 53$ independent induction of $\mathrm{p} 21$. Jung et al. [13] studied glioblastoma tumors (high grade). Both p 53 dependent and $\mathrm{p} 53$ independent mechanisms of p21 activation account for $\mathrm{p} 21$ expression in these tumors.

Erber et al. [14] found that p21 accumulation was independent of the genetic status of p53 in head and neck tumors.

Rey et al. [15] studied p21 expression, which was independent of $\mathrm{p} 53$ overexpression in breast cancer. Only 20 carcinomas showed p53 overexpression but 
p21 was negative in these cases, thus providing evidence for the existence of $\mathrm{p} 53$ independent mechanisms for p21 regulation.

Yook and Kim [12] reported that the expression of p21 was independent of $\mathrm{p} 53$ in oral squamous cell carcinoma. p21 was expressed in 15 out of 20 cases. Of the 13 tumors, which were the wild type for $\mathrm{p} 53,9$ showed positive staining for $\mathrm{p} 21,6$ out of the 7 cases with demonstrated $\mathrm{p} 53$ mutations stained similarly for $\mathrm{p} 21$.

The results of carcinoma arising in pleomorphic adenoma showed that 12 cases $(44.4 \%)$ expressed moderate or strong staining of $\mathrm{p} 53$. This is comparable to the frequencies of $67 \%$ [16] and $75 \%$ [3] reported in the literature. Also p21 staining was positive in 14 $(51.8 \%)$ cases out of 27 . All of these results are consistent with literature.

Li et al. [17] studied the numeric aberrations of chromosome 17 and p53 gene deletion carcinomas arising in pleomorphic adenoma. Polysomy was observed in $19.6 \%$ of carcinoma cells, and monosomy of chromosome 17 was shown in $30.8 \%$ of CPA cells (carcinoma in pleomorphic adenoma). Immunohistochemical staining showed p53 was expressed in 6 out of 9 CPA cases $(66.7 \%)$. Yamamoto et al. [18] found a high rate of mutations (loss of heterozygosity) as the $\mathrm{p} 53$ gene was detected in cases of carcinoma arising in pleomorphic adenoma (58\%). Nordkvist et al. [19] studied 24 cases of carcinoma ex pleomorphic adenoma. 17 cases showed $\mathrm{p} 53$ expression. 9 cases with positive p53 staining had $1-10 \%$ of positive cells, 5 cases showed positive p53 staining in $11-50 \%$ of the cells, and 3 cases showed very strong staining of $\mathrm{p} 53$ in $51-100 \%$ of the cells. $\mathrm{p} 21$ belongs to a class of tumor suppressors including p16 and p27, which control progression through the cell cycle by inhibiting the activity of cyclin-cdk complexes. De Lima et al. [20] reported that no expression of p21 was found in adenoid cystic carcinomas. Tarakji and Nassani [21] reported that p21 was strongly expressed in carcinoma arising in pleomorphic adenoma in $9(33.3 \%)$ cases out of 27 . In view of the central role of p21 in inducing growth arrest, terminal differentiation, or apoptosis, alterations in p21 expression may reflect a vital role in the pathogenesis of carcinoma arising in pleomorphic adenoma in both $\mathrm{p} 53$ dependent and independent cases. The published literature on tumor markers in CPA is limited due to the fact that these tumors are rare. The present results are consistent with these studies.

\section{Conclusions}

These results suggest that induction of p21 occurs by both $\mathrm{p} 53$ dependent and independent mechanisms during development of carcinoma arising in pleomorphic adenoma.

The authors declare no conflict of interest.

\section{References}

1. Suzuki H, Fujioka Y. Deletion of the p16 gene and microsatellite instability in carcinoma arising in pleomorphic adenoma of the parotid gland. Diagn Mol Pathol 1998; 7: 224-231.

2. Numata T, Hiruma K, Tsukuda T, Asano T. Malignant mixed tumor. Gan to Kagaku Ryoho 2004; 31: 314-317.

3. Yamamoto Y, Kishimoto Y, Wistuba II, et al. DNA analysis at $\mathrm{p} 53$ locus in carcinomas arising from pleomorphic adenomas of salivary glands: comparison of molecular study and p53 immunostaining. Pathol Int 1998; 48: 265-272.

4. Kudo Y, Takata T, Ogawa I, et al. Expression of p53 and p21CIP1/WAF1 proteins in oral epithelial dysplasias and squamous cell carcinomas. Oncol Rep 1999; 6: 539-545.

5. Michalides R, Hageman P, van Tinteren H, et al. A clinicopathological study on overexpression of cyclin D1 and of p53 in a series of 248 patients with operable breast cancer. Br J Cancer 1996; 73: 728-734.

6. Bau DT, Tsai MH, Lo YL, et al. Association of p53 and p21(CDKN1A/WAF1/CIP1) polymorphisms with oral cancer in Taiwan patients. Anticancer Res 2007; 27: 1559-1564.

7. el-Deiry WS, Tokino T, Velculescu VE, et al. WAF1, a potential mediator of $\mathrm{p} 53$ tumor suppression. Cell 1993; 75: 817-825.

8. el-Deiry WS, Harper JW, O'Connor PM, et al. WAF1/CIP1 is induced in p53-mediated G1 arrest and apoptosis. Cancer Res 1994; 54: 1169-1174.

9. Harada K, Ogden GR. An overview of the cell cycle arrest protein, p21(WAF1). Oral Oncol 2000; 36: 3-7.

10. Nagao K, Matsuzaki O, Saiga H, et al. Histopathologic studies on carcinoma in pleomorphic adenoma of the parotid gland. Cancer 1981; 48: 113-121.

11. Chen HH, Lee LY, Chin SC, et al. Carcinoma ex pleomorphic adenoma of soft palate with cavernous sinus invasion. World J Surg Oncol 2010; 8: 24.

12. Yook JI, Kim J. Expression of p $21 \mathrm{WAF} 1 / \mathrm{CIP} 1$ is unrelated to p53 tumour suppressor gene status in oral squamous cell carcinomas. Oral Oncol 1998; 34: 198-203.

13. Jung JM, Li H, Kobayashi T, et al. Inhibition of human glioblastoma cell growth by WAF1/Cip 1 can be attenuated by mutant p53. Cell Growth Differ 1995; 6: 909-913.

14. Erber R, Klein W, Andl T, et al. Aberrant p21(CIP1/WAF1) protein accumulation in head-and-neck cancer. Int J Cancer 1997; 74: 383-389.

15. Rey MJ, Fernández PL, Jares P, et al. p21WAF1/Cip1 is associated with cyclin D1CCND1 expression and tubular differentiation but is independent of $\mathrm{p} 53$ overexpression in human breast carcinoma. J Pathol 1998; 184: 265-271.

16. Deguchi H, Hamano H, Hayashi Y. c-myc, ras p21 and p 53 expression in pleomorphic adenoma and its malignant form of the human salivary glands. Acta Pathol Jpn 1993; 43: 413-422.

17. Li X, Tsuji T, Wen S, et al. Detection of numeric abnormalities of chromosome 17 and $\mathrm{p} 53$ deletions by fluorescence in situ hybridization in pleomorphic adenomas and carcinomas in pleomorphic adenoma. Correlation with p 53 expression. Cancer 1997; 79: 2314-2319.

18. Yamamoto Y, Kishimoto Y, Virmani AK, et al. Mutations associated with carcinomas arising from pleomorphic adenomas of the salivary glands. Human Pathol 1996; 27: 782-786.

19. Nordkvist A, Röijer E, Bang G, et al. Expression and mutation patterns of $\mathrm{p} 53$ in benign and malignant salivary gland tumors. Int J Oncol 2000; 16: 477-483.

20. de Lima Mde D, Marques YM, Alves Sde M Jr, et al. MDM2, $\mathrm{P} 53, \mathrm{P} 21 \mathrm{WAF} 1$ and $\mathrm{pAKT}$ protein levels in genesis and behaviour of adenoid cystic carcinoma. Cancer Epidemiol 2009; 33: $142-146$

21. Tarakji B, Nassani MZ. Immunohistochemical expression of p21 in normal tissues of salivary gland, pleomorphic adenoma and carcinoma ex pleomorphic adenoma-(undifferentiated and adenocarcinoma types). Med Oral Patol Oral Cir Bucal 2010; 15: e697-703. 